\title{
On the issue of improving the efficiency of environmental management in the coastal zone of the Onega Lake
}

\author{
Alexandr Sanin ${ }^{*}$ \\ Zubov State Oceanological Institute, 119034, 6, Kropotkinskij st., Moscow, Russia
}

\begin{abstract}
This article is the result of a research conducted in the Zubov State Oceanological Institute during 2014-2019. The research was aimed at studying the coastal dynamics, as well as evaluating the quality of waters of the Onega Lake and the impact of natural and anthropogenic factors on it. Those factors were considered and characterized, the most important of them, in addition to human activity, are the solid flow of rivers and the flow from abrasion processes. Seven types of coasts were identified for the Onega Lake, each of which has its own characteristics of dynamic processes and the impact of natural and anthropogenic factors on water quality. The dynamics of the coasts were analyzed both in the course of field studies and using mathematical modeling methods, which allowed revealing the main tendencies in the dynamics of the coasts. Pollutants entering the Lake and affecting the quality of water are also divided by origin into natural, anthropogenic and mixed genesis pollutants. Special attention is paid to the natural sources of pollution, since they are considered in the available literature to the least extent. Natural origin pollutants include, in particular, the majority of heavy metals, which concentrations for various sites were determined during the research.
\end{abstract}

\section{Interaction}

It is difficult to overestimate the importance of preservation the water of Lake Onega. Both natural and anthropogenic factors influence over the lake's waters, they determine the amount of pollutants received and the processes of their transportation. The impact of the natural factors is usually not taken into account, but the example of Lake Onega shows that it can be crucial for many pollutants, such as heavy metals. Natural factors play a particularly important role for the lake's water area with minimal human activity, and there are quite a lot of such areas in the Onega region. The natural sources of pollution of the Lake Onega waters include the receipt of pollutants from river flow, which provides the main contribution to the pollution of the Lake from natural sources, up to $70 \%$ [1]. A quite important role is played by the flow during abrasion processes, which has a decisive impact on some areas. To determine the contribution of river flow of solid matter, it is necessary to know all about their hydrological characteristics and some features of their water basins. In

*Corresponding author: eather86@mail.ru 
particular, it is necessary to be aware of the level of thickness and mineralogical consistence of quaternary sediments lying on the surface and eroded by rivers. The article sets the following tasks that determined its structure.

1. Characterize the physical and geographical features of Lake Onega and identify the types of its coasts.

2. Show the necessity of taking into account adverse and dangerous natural processes in the management of human activity in the region.

3. Identify and characterize the factors that affect water quality.

4. Propose the measures that will preserve the quality of the lake's waters and reduce the severity of conflicts between different types of human activities in the region.

\section{Physical and geographical features of Lake Onega and types of its coasts}

Lake Onega is characterized by various natural conditions and levels of economic development, therefore, environmental management in the region must take into account local specialties, for instance, in applying the chapters of the Code of Water Resources and other requirements of current environmental regulations.

The level of stability of the coasts is determined by the processes of abrasion and accumulation. In their turn, intensity of these processes is determined by the characteristics of the shore-forming rocks and sediments. In the northern part of the Lake there are PreCambrian crystalline rocks, covered only with a thin layer of Quaternary sediments. The rest of the lake's coasts are usually formed by Quaternary sediments. They are less resistant to wave action. As a rule, their thickness varies from several meters to several tens of meters [2]. Geoprofiling showed a small amount of modern beach deposits in most cases, which indicates the vulnerability of beaches in the event of Lake level rising and (or) wave impact increasing. Lake level can rise due to different reason, for example due to an increase in precipitation which is observed [3].

Seven morphogenetic types of coasts have been identified for Lake Onega: primary, abrasive, abrasive-accumulative, accumulative, lagoon, delta, and anthropogenic [2]. Each type has specific features of dynamic processes. In particular, for abrasive and abrasiveaccumulative coasts, which are most typical for the East and West part of Lake, the processes of active wave processing of the coast are typical. In some areas, for example, near the villages of Kaskes-Ruchey, Kurshevo, Golyashi, etc. it can threaten the buildings. In some cases, the abrasion can also destroy the roads near the coastline. The processes of accumulation of material on the underwater coastal slope are typical for delta and accumulative coasts. They can lead to shallowing of some parts of lake used for navigation of ships approaching to the coastline.

\section{Influence of adverse and dangerous natural processes}

The experience acquired from studying a large number of seas and inland water objects of the Russian Federation shows the negative impact of natural dangerous processes on people's lives and health. The activities of most of them can also lead to significant material damage [4]. Storm waves, abrasion processes on the lake's coasts, water logging of the territory, and some others are the most dangerous phenomenon affecting Lake Onega and its basin territory[5,6].

According to [2] and to the results of own observations, the intensity of abrasion processes is generally small and rarely exceeds tens of centimeters per year. However, in some areas, abrasion processes can be a threat for buildings and objects situated near the 
coastline, as well as affect the quality of water. Strong winds can be dangerous for ships, especially for boats, including those carrying tourists.

To improve the effectiveness of environmental management, a number of measures should be taken to increase a negative effect from natural dangerous processes.

- Minimization (if possible) of economic use of coastal areas where adverse and dangerous natural processes are the most active, in particular, parts of coastal zone with active landslides and abrasion processes.

- Informing recreants and local residents about the risks and dangers to their life and health caused by adverse and dangerous natural processes.

- Protection of the areas of the coasts which are most attractive for economic activity. Among the possible ways of protection are the following: the implementation of coasts protection works (methods of so-called soft and hard coasts protection can be applied), antilandslide measures, construction of breakwaters, etc.

- Prohibition of building activity in the beach area due to the threat from storm waves.

-- Monitoring of adverse and dangerous natural processes at least in those areas where they are mostly observed and threaten recreants and local residents.

\section{Factors affecting water quality}

Both natural and anthropogenic factors affect water quality contributing to the flow of pollutants and reducing its quality. Many pollutants arrive mainly due to natural factors, such as river flow of solid matter, processes of abrasion, as well as a result of exchange with bottom and shore sediments [5].

Analysis of water use in the Onega lake basin showed that at least 28 types of pollutants are discharged into it. They can be divided into 5 groups.

- general (4) (dry residue, suspended solids, easily and hard-to-oxidize organic substances (in terms of biochemical oxygen consumption (total) and chemical oxygen consumption );

- main ions (4) (sulfates, chlorides, calcium, magnesium);

- biogenic substances (5) (common nitrogen, ammonium nitrogen, nitrites, nitrates, phosphates);

- metals (9) (iron, manganese, aluminum, zinc, copper, nickel, chromium (III, VI), lead);

- complex organic compounds (6) (petroleum products, synthetic surface-active substances, methanol, formaldehyde, phenols, ammonium lignosulfonate).

On the basis of a long-term series of observations (2008-2017), the author developed updated classification of water pollutants by their genesis. This allowed singling out anthropogenic and natural factors affecting water quality of Lake Onega, which can increase the effectiveness of water protection measures. Three groups of pollutants based on their genesis have been identified for Lake Onega and its hydrographic basin:

1) Pollutants of artificial origin or xenobiotics (substances foreign to water): petroleum products, synthetic surface-active substances, methanol, formaldehyde, phenols, ammonium lignosulfonate;

2) Pollutants which have mixed genesis (enter the water under the influence of both natural and anthropogenic factors): suspended substances, sulfates, chlorides, calcium, magnesium, common nitrogen, ammonium nitrogen, nitrites, nitrates, phosphates, iron, manganese, aluminum, zinc, copper, nickel, chromium (III, VI), lead and some others.

3) Pollutants of natural origin (enter the water under the influence of natural factors): cobalt, cadmium, arsenic, vanadium, titanium.

The intake rate of pollutants coming from natural sources depends on the types of coasts. Each type is characterized by its own dynamic processes, which influences 
transportation of pollutants as well as on the volume of river flow of solid matter and its mineralogical composition. It is logical to assume that the flow of pollutants from river flow of solid matter is greatest for delta coasts with form near river mouths. On the other hand, such source of pollutant transportation is important from the accumulative coasts if a significant part of the accumulated material is brought by rivers and streams. It is logical to expect the highest intensity of incoming of pollutants with the processes of abrasion of such types of coasts as abrasive and abrasive-accumulative. Especially in case when there are no rivers in this part of coastline due to abrasion incoming pollutants should be considered as the dominant ones. Finally, even the name "anthropogenic coasts" indicates that for this type the greatest role in many cases is played by anthropogenic sources of pollutants.

Lake Onega is characterized by a complicated structure of water currents, which influence the distribution of pollutants within the Lake significantly. In particular, a fairly well-defined circular flow directed counterclockwise was formed [6]. It provides transportation of the pollutants which arrive as a result of abrasion and with river flow of solid matter and to areas adjacent to those where abrasion occurs and within which rivers flow.

Currently, general concentrations of all pollutants are lower than permissible level of pollution. Therefore, in most cases water can be used for drinking needs. The threshold level values are exceeded only in certain small water areas, for example, in the Petrozavodsk or Kondopoga Bay. There are parts of Onega Lake which face the greatest anthropogenic impact. In general the concentrations of pollutants are not very high largely due to the large volume of water contained in the Lake. However, in the future they can increase due to the possible activation of income from both natural and anthropogenic sources.

In particular, possible reasons for increasing the volume of incoming pollutants are:

- intensification of agricultural use of the territory, which leads to an increase in the volume of nutrient pollutants, nitrogen and phosphorus.

- construction works in the territory of the hydrographic basin, which lead to the formation of numerous open ground dumps, eroded by rivers and temporary streams. Due to this, river flow of solid matter, which contains pollutants, increase. The same negative consequences can occur in the case of increasing the intensity of mining, in particular, construction raw materials, and the increasing of number of careers.

- increasing the number of small motorized vessels and the numbers of their usage.

- reduction of forests within the hydrographic basin of Onega Lake.

- unauthorized dumps within the hydrographic basin of the Lake.

- increase of the average wind speed, which will lead to increased wave activity as well as abrasion.

- rise of the Lake's water level due to natural or anthropogenic reasons, which will also lead to activation of abrasion of the coasts

- increase the sum of precipitation, which will increase the volume of water entering rivers flowing into the Lake, in particular, the volume of their solid flow.

- increase of winter temperatures, which will increase the duration of the ice-free period, and, consequently, the impact of waves on the coasts of Onega Lake.

For certain areas of region the influence of these factors in the present time have been described. For instance, such processes as unauthorized landfills, deforestation, activation of garden associations and mining of building stone have already caused an increase in the volume of pollutants coming from the rivers of the South-West of the region [7]. 


\section{Measures to preserve the quality of the Lake's waters and reduce the severity of environmental conflicts in the region}

The modern economy of the Onega Lake basin is characterized by a complex structure. Onega region is characterized by forest, wood processing, pulp and paper, mining, light, food and fishing industries, and agriculture. Machine-building and metalworking, shipbuilding and ship repair production are developing there as well. Lake Onega is an important water transport hub connecting the basins of the White, Baltic, Caspian, Azov, and Black seas. The total length of navigable routes on the Lake is $1862 \mathrm{~km}$ [5].

Mitigation of environmental management conflicts is possible if we take into account the interests of both participants to the conflict and understanding their purposes. Often, the causes of conflicts between different types of human activity are in competition between each other for the same resources, in particular, territory.

Specifically, for the Onega Lake region, intense competition of types of human activity is not common, as the intensity of economic activity in the region as a whole is relatively low. On the other hand, for most parts of the Onega's drainage basin there is no lack of human activities. The lake basin is the most economically developed part of the Republic of Karelia [5]. Water resources of the region are intensively used for industrial purposes, as an economic and drinking water to supply to the population. More over Onega's water has recreational, fishery and environmental importance. There may be the contradictions between different economic activities. Some types of human activity, in particular, residential and industrial activities, inevitably compete. An example is the conflict between nature conservation and recreational activity in the territory of the Kizhi islands. It is the world-famous open-air museum of wooden architecture.

To preserve the quality of Lake water it is necessary to take a number of different measures for the whole territory of the Onega Lake region. In particular, it is recommended to carry out further work on marking the borders of water protection zones and coastal protective zones and fixing the borders of zones with special information signs. These actions will help to ensure compliance with environmental law within the water protection zones and coastal protective zone, as many violations of restrictions, for them, such as dumping ground or unorganized parking, lead to increased inflow of pollutants into the Lake. It is important to note that water protection zones and coastal protective zones need to be allocated not only directly around Lake Onega, but also around the rivers flowing into the Lake. Water objects (coasts, water area and water protection zones) need to be monitored, in particular for hydrochemical indicators of water. It is expected that monitoring of the water protection zone will reduce the number of violations of the rules of its use, which take place due to the threat of implementation of the foreseen penalties for such actions.

At the same time control of wastewater treatment of large cities and industrial zones is vital and can be even more effective.

In order to assess the impact of small size vessels on the water quality of Lake Onega as correctly as possible it is recommended to study the issue of control over the regime of operation of boats on the water area of Lake Onega (including unregistered). Organization of boats parking bases as well as the establishment of zones of possible unorganized parking lots of boats is necessary. Such boats and water transport as a whole is the main contribution to the share of petroleum products in the waters of Lake Onega ( $61 \%$ of total revenue [5]).

Coastal areas with the highest intensity of abrasion and erosion processes and the highest degree of economic development are in need of coastal protection. Abrasiveaccumulative and especially abrasive coasts may need protection if they have infrastructure objects near the coastline: buildings, roads, etc., the defense of such objects is especially 
actual in case the rates of coasts receding are significant. In many cases, however, it may be preferable and cheaper to move infrastructure objects inland instead of protection them.

It is recommended to consider expanding the network of natural reserves in the region. Currently there are seven such territories of federal and regional level with the total area of about 606.7 thousand hectares in the watershed [1]. However, their distribution is very uneven; most of this area is accounted for by the national park "Vodlozersky", directly on the coast of Lake Onega and its islands protected areas occupy relatively small areas.

\section{Conclusions}

For Lake Onega seven main types of coasts can be distinguished. Each of them has its own peculiarities of dynamic processes and inflow of pollutants. Different factors, such as anthropogenic impact and its components, river flow of solid matter and the impact of abrasive processes, contribute to the inflow of pollutants for different types of coasts. The subsequent distribution of pollutants in the Lake is noticeably affected by water currents.

The considerable volume of the Lake waters by now provides reduction of concentration of the majority of pollutants for the most part of water area to values not exceeding admissible concentration limit. The total water quality assessment showed that $60 \%$ of water bodies in the Onega Lake basin correspond to "good" water quality. $21 \%$ of water bodies, including Lake Onega, have "high" water quality and 14\% of water bodies have "satisfactory" water quality. The remaining $5 \%$ of water bodies are characterized by "low" water quality, due to active anthropogenic activities.

However, using the example of parts of Lake Onega that experience the highest anthropogenic impact and are partially isolated from the rest of the water area (e.g., Kondopoga Bay), as well as other bays of the seas and inland water bodies, it can be seen that admissible concentration limit can be exceeded by increasing the intake of pollutants from both natural and anthropogenic sources.

The reported study was funded by RFBR according to the research project № 18-35-00545.

\section{Reference}

1. N.N. Filatov. Onezhskoye Lake. Atlas, (2010)

2. E.I. Ignatov, E.V. Borschenko, A.L. Zagoskin, I.V. Zemlyanov, A.Y. Sanin, P.N. Tersky, M.O. Fathi, Proceedings of the Karelian scientific centre RAS, series Limnology, 3, (2017), 65-78.

3. N.N. Filatov, Arctic: ecology and economy, № 2, 6, (2012), 80-93.

4. V.M. Kutepov, A.I. Sheko.Natural Hazards of Russia, 3, 348, (2002)

5. N.N. Filatov. The largest lakes-reservoirs of the North-West of the European territory of Russia: the current state and changes in ecosystems under climatic and anthropogenic impacts (2015)

6. N.N.Filatov. Onezhskoye Lake. Ecological Problems (1999)

7. A.V. Sabylina,T.V. Efremova, Ecological chemistry,№ 26, 6, 333-339 (2017) 